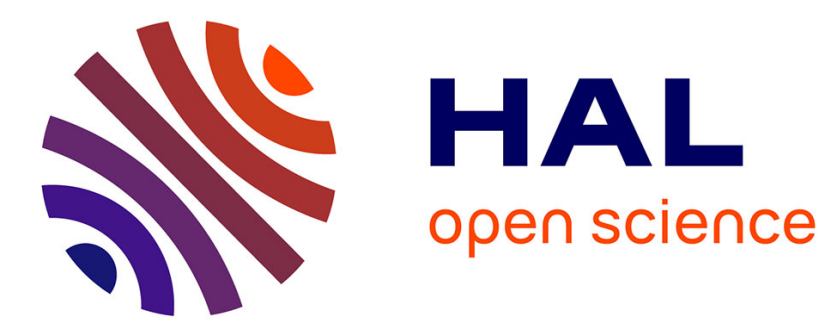

\title{
On Linguistic Evidence for Expressivism
}

Andrés Soria Ruiz, Isidora Stojanovic

\section{To cite this version:}

Andrés Soria Ruiz, Isidora Stojanovic. On Linguistic Evidence for Expressivism. Philosophy, 2019, 10.1017/S1358246119000110 . hal-02522706

\section{HAL Id: hal-02522706 \\ https://hal.science/hal-02522706}

Submitted on 25 Apr 2020

HAL is a multi-disciplinary open access archive for the deposit and dissemination of scientific research documents, whether they are published or not. The documents may come from teaching and research institutions in France or abroad, or from public or private research centers.
L'archive ouverte pluridisciplinaire HAL, est destinée au dépôt et à la diffusion de documents scientifiques de niveau recherche, publiés ou non, émanant des établissements d'enseignement et de recherche français ou étrangers, des laboratoires publics ou privés. 


\title{
On linguistic evidence for expressivism
}

\author{
Andrés Soria Ruiz and Isidora Stojanovic
}

\begin{abstract}
This paper argues that there is a class of terms, or uses of terms, that are best accounted for by an expressivist account. We put forward two sets of criteria to distinguish between expressive and factual (uses of) terms. The first set relies on the action-guiding nature of expressive language. The second set relies on the difference between one's evidence for making an expressive vs. factual statement. We then put those criteria to work to show, first, that the basic evaluative adjectives such as 'good' have expressive as well as factual uses and, second, that many adjectives whose primary meanings are factual, such as 'powerful', also have expressive uses.
\end{abstract}

\section{Introduction}

Non-factualism or expressivism names a broad family of views originally about the meaning of moral vocabulary, but that has been extended to other parcels of natural language, notably perspectival expressions. Besides moral discourse, there are expressivists about normative language, epistemic modals, the a priori, conditionals, knowledge attributions or predicates of personal taste. ${ }^{1}$

Expressivism can be stated as a thesis about a certain parcel or fragment of declarative sentences of natural language, let us call it ' $F$ '. The expressivist claims that even though F-sentences look like any other declarative sentence, they are importantly different. More specifically, whereas the usual communicative function of declarative sentences is to describe reality, the function of Fsentences is not. Expressivists say that the function of F-sentences is 'non-representational', 2 that

\footnotetext{
${ }^{1}$ Allan Gibbard, Wise Choices, Apt Feelings (Oxford University Press, 1990), and Thinking how to live (Harvard University Press, 2003); Seth Yalcin. 'Epistemic modals' Mind 116(464) (2007), 983-1026; Hartry Field, 'Apriority as an evaluative notion', in Christopher Peacocke and Paul A Boghossian (Eds.), New Essays on the a Priori, 11749 (Oxford University Press, 2000); Gibbard, Allan. 'Two Recent Theories of Conditionals', in William L Harper, Robert Stalnaker, and Glenn Pearce (Eds.) IFS: Conditionals, Belief, Decision, Chance and Time, 211-47 (Dordrecht: Springer Netherlands, 1981); Matthew Chrisman, 'From Epistemic Contextualism to Epistemic Expressivism' Philosophical Studies 135 (2007), 225-54; David Bordonaba Plou, Operadores de orden superior y predicados de gusto: Una aproximación expresivista (PhD thesis, Universidad de Granada, 2017); Daniel Gutzmann 'If expressivism is fun, go for it!' in Cécile Meier and Janneke van Wijnberger-Huitink (Eds.), Subjective Meaning: Alternatives to Relativism, 21-46 (De Gruyter, 2016).
}

2 Nate Charlow, 'The problem with the Frege-Geach problem' Philosophical Studies 167(3) (2014), 635-65. 
is, its function is not to describe 'ways the world is', ${ }^{3}$ or 'how things stand' ${ }^{4}$ Sometimes these views are presented as committed to the idea that the F-sentences are 'not straightforwardly factual'.$^{5}$ All in all, expressivism is first and foremost a negative thesis:

(Expressivism): F-sentences do not describe the way the world is.

Traditionally, expressivism has been motivated on metaphysical, epistemological and motivational or psychological grounds. Relative to each of these three areas, the argumentative strategy has been to claim that an alternative, factualist (or descriptivist) account of F-sentences has undesirable commitments or is explanatorily unsatisfactory. ${ }^{6}$

To see this, let's focus on the case of morality. Factualism about moral discourse is the view that moral predicates and moral sentences describe reality. This view is committed to the existence of moral facts and properties (those described by moral vocabulary). Furthermore, moral factualism requires a story about moral epistemology (how we come to know, or be acquainted with, moral facts and properties). And given the action-guiding properties of moral thought and language, the factuality story requires an explanation of how the mere apprehension of facts and/or acquaintance with properties motivates action. Given certain naturalistic priors, factualism about morality incurs an undesirable metaphysical commitment - a commitment to the existence of moral properties and moral facts. And factualist accounts of both moral epistemology and psychology have been claimed to be explanatorily deficient. Expressivists about moral discourse, by contrast, claim to be free from such commitments and explanatory gaps. By refusing to assign properties as the meaning of moral predicates, or moral facts as the meaning of moral sentences, expressivists eschew a commitment to populating the world with metaphysically spooky entities. By the same token, expressivists need not give any story about we come to know and learn about those properties and facts. And finally, they are free to offer an alternative account of how moral judgment motivates action, one which does not rely on an obscure connection between apprehension of facts and practical motivation.

\footnotetext{
3 María José Frápolli and Neftalí Villanueva, 'Minimal expressivism’ Dialectica 66(4) (2012), 471.

${ }^{4}$ Gideon Rosen, 'Critical study of Blackburn’s Essays in Quasi-Realism’ Noûs 32(3) (1998), 388.

5 Hartry Field, 'Epistemology without metaphysics' Philosophical Studies 143(2) (2009), 249-90, and

'Epistemology from an Evaluativist Perspective' Philosopher's Imprint 18(12) (2018), 1-23; Seth Yalcin 'Bayesian Expressivism' Proceedings of the Aristotelian Society (Hardback) 112 (2012), 123-60.

${ }^{6}$ Elizabeth Camp, 'Metaethical Expressivism' In Tristam MacPherson and David Plunkett (Eds.), The Routledge Handbook of Metaethics, 87-101 (Routledge, 2017).
} 
However, there is something very odd about expressivism: even though it is presented as a view about language, it has hardly ever been defended on linguistic grounds. ${ }^{7}$ And that is not just a historical or dialectical contingency. For it is not even clear that there is, or can be, any linguistic evidence for expressivism. Indeed, the main problem that expressivism faces, the Frege-Geach problem, stems from the fact that the linguistic behavior of F-sentences and other declarative sentences is largely uniform. Schroeder puts the matter bluntly when he discusses moral expressivism: '[t]here is no linguistic evidence whatsoever that the meaning of moral terms works differently than that of ordinary descriptive terms. On the contrary, everything that you can do syntactically with a descriptive predicate like 'green', you can do with a moral predicate like 'wrong', and when you do those things, they have the same semantic effects' ${ }^{8}$

The purpose of this paper is to rebut Schroeder's claim. We argue that there is a class of terms, which we will call expressive terms, that in their central uses are linguistically different from descriptive (or factual) terms and that call for an expressivist account. ${ }^{9}$ Pace Schroeder, there is linguistic evidence that expressive terms pattern differently from descriptive terms, even though this evidence may be more subtle than what he seems to have in mind. ${ }^{10}$

\footnotetext{
${ }^{7}$ Although originating in the philosophical literature, Moore's "Open Question" and "What's at Issue?" arguments might arguably be viewed as linguistic criteria or tests in favor of the specificity of evaluative language. See George Edward Moore, Principia Ethica (Cambridge University Press, 1903/1993) and Allan Gibbard, Thinking how to live (Harvard University Press, 2003, pp. 23 and ff.).
}

${ }^{8}$ Mark Schroeder, 'What is the Frege-Geach Problem?' Philosophy Compass 3(4) (2008), 704, his emphasis.

9 Why speak of expressive and not evaluative terms? Simply put, because there is no consensus in the literature on what 'evaluative' means. In the philosophical literature, it is common to speak of evaluative terms as those that carry appraisal or evaluation and that figure in value judgments (see e.g., Pekka Väyrynen, The Lewd, the Rude, and the Nasty, 29 and ff. (Oxford University Press, 2013)). In the linguistics literature, by contrast, 'evaluativity' often refers to the phenomenon by which a gradable adjective makes reference to a contextually determined threshold (Manfred Bierwisch 'The semantics of gradation' In Manfred Bierwisch and Ewals Lang (Eds.), Dimensional Adjectives, 71261 (Springer-Verlag, 1989); Jessica Rett, 'Antonymy and evaluativity', in T. Friedman and M. Gibson (Eds.) Proceedings of SALT XVII, 210-27, (Cornell University, 2007)). Furthermore, on the one hand 'evaluative' is sometimes used interchangeably with 'subjective' (Chris Kennedy, 'Two Sources of Subjectivity: Qualitative Assessment and Dimensional Uncertainty' Inquiry 56(2-3) (2013), 258-77). But on the other hand, 'evaluative terms' are sometimes opposed to predicates of personal taste, only the latter of which are deemed subjective (Louise McNally and Isidora Stojanovic, 'Aesthetic Adjectives' In James Young (Ed.), The Semantics of Aesthetic Judgment, (Oxford University Press, 2017); Isidora Stojanovic, 'Disagreements about Taste vs. Disagreements about Moral Issues'. American Philosophical Quarterly 56 (2019): 29-41.

10 There have been attempts to appeal to linguistic evidence in defense of expressivism, to wit: Seth Yalcin's work on epistemic modals (Yalcin 2007 op.cit) and, more recently, Nils Franzén, Sense and Sensibility: Four Essays on Evaluative Discourse PhD thesis (University of Uppsala, 2018). Our take is very different from these authors' take, however. 
We put forward two sets of criteria to distinguish between expressive and factual (uses of) terms. The first set ( $\$ 2)$ relies on the action-guiding nature of expressive language. The second set ( 33$)$ relies on the difference between one's evidence for making an expressive vs. factual statement. In $\S 4$ we put those criteria to work. We aim to show, first, that the basic evaluative adjectives such as 'good' have expressive as well as factual uses (\$4.1) and, second, that many adjectives whose primary meanings are factual, such as 'powerful', also have expressive uses (§4.2).

Before we proceed, a clarification is in order. In linguistics, by 'expressive terms' one would typically mean an arguably distinct syntactic class of terms, namely interjections such as 'wow', or 'fuck', modifiers such as 'fucking' or 'damned', or epithets such as 'asshole'. ${ }^{11}$ Here, we will not be concerned with those expressives. Rather, we will focus on expressions from the same syntactic categories as the usual factual vocabulary, and more specifically, on adjectives. We will be speaking of adjectives as having expressive vs. factual meaning, and we will be distinguishing between expressive vs. factual uses of certain adjectives. ${ }^{12}$

\section{Action-guidance, practical commitments and expressive language}

The literature on normativity has long recognised the idea that moral adjectives and, more generally, adjectives with expressive meaning have a special connection to action and motivation. ${ }^{13}$ The idea is that when a rational speaker expresses something positive about an object, they should eo ipso be inclined to act in favor of that object; and similarly, if they express something negative, they should eo ipso be inclined to act against it.

For instance, if a rational speaker judges football to be a 'great' sport, we expect her to be willing to watch it, play it or support it somehow. By contrast, if she judges football to be a 'popular' sport, there is no comparative expectation about what her practical attitudes towards football will be (or else, such an expectation will be based on some other action-guiding attitude of hers). This

\footnotetext{
${ }^{11}$ Christopher Potts, The logic of conventional implicatures (Oxford University Press, 2005); Elin McCready, 'Emotive Equilibria', Linguistics and Philosophy 35 (2012): 243-283; Daniel Gutzmann, The Grammar of Expressivity (Oxford University Press, 2019).

12 To forestall a possible confusion, we are not claiming that an expression has either a factual or an expressive meaning, nor are we claiming that any given use of an expression is either factual or expressive. For instance, thick terms - that is, adjectives such as 'generous' or 'lewd' - arguably have both a factual (or descriptive) and an expressive (or evaluative) dimension to their meaning, and can used both factually and expressively at the same time. For discussion, see Bianca Cepollaro and Isidora Stojanovic, Isidora, 'Hybrid Evaluatives: In Defense of a Presuppositional Account' Grazer Philosophische Studien 93 (3) (2016): 458-488; Pekka Väyrynen, 'Thick Ethical Concepts', in Edward Zalta (ed.), Stanford Encyclopedia of Philosophy (2016).
}

13 Richard M. Hare, The language of Morals (Oxford Paperbacks, 1952); James Dreier, 'Internalism and speaker relativism' Ethics 101 (1) (1990), 6-26; Fredrik Björklund, Gunnar Björnsson, John Eriksson, Ragnar Francén Olinder, and Caj Strandberg, 'Recent work on motivational internalism' Analysis 72 (1) (2011): $124-137$. 
is what Stevenson called the 'magnetism' of evaluative vocabulary - the good is attractive; the bad is repulsive. ${ }^{14}$

This action-guiding potential that characterises terms with expressive meaning gets reflected on two fronts. First, a speaker who applies such a term to an object thereby demonstrates her own practical commitments. If you say something positive about football, you practically engage yourself towards acting in its favor (to the relevant extent). ${ }^{15}$ Second, a hearer who accepts the speaker's utterance will also, in doing so, alter her own practical commitments. If you say that football is great and your audience does not object, then they, too, practically engage themselves towards acting in favor of football.

Let us illustrate the idea with more examples. Consider the following three:

(1) It is horrible to pull a fire alarm for fun.

(2) It is uncommon to pull a fire alarm for fun.

(3) It is illegal to pull a fire alarm for fun.

If the speaker of (1) is sincere, then normally, she will be expressing a certain practical stance against performing the kind of action under evaluation, namely pulling fire alarms for fun. The speaker will commit to rejecting, avoiding and condemning any action of that kind. ${ }^{16}$ What is more, if the audience of (1) accepts it, then they, too, will be normally adopting that same disapproving practical stance towards that kind of action. ${ }^{17}$

One way to see this is that there would be a strong incoherence if one agreed on (1) and then went on to pull a fire alarm just for fun. In contrast to this, both in the case of (2) and (3), there is no similar practical commitment carried either by the speaker or by the audience. One can

\footnotetext{
${ }^{14}$ Charles L. Stevenson, 'The Emotive Meaning of Ethical Terms' Mind 46 (181) (1937), 14-31.

${ }^{15}$ Of course, one's attitudes towards an object can often be complex, including both positive and negative aspects. For instance, a person might say 'I don't doubt that football is a great sport, but it has caused so much violence, and I just cannot stand all the corruption and filthiness of that whole football industry. That's why I hate football.' Hence the claim that saying something positive invites the inference that the speaker will act in favor of the object under evaluation is to be read with an implicit ceteris paribus.
}

16 This leaves room for certain exceptions, in which a speaker, however sincere, may fail to express a practical stance that one would normally express. This can happen when one is self-deceived about their own attitudes. Consider a professor who tell a junior colleague: "You are lucky that you paper has been published in such a prestigious journal". He may sincerely intend to express a positive stance, yet what he express is condescension, which isn't positive at all.

${ }^{17}$ Note that failing to object or reply to your interlocutor doesn't necessarily mean that you accept what they say. They may be reasons - social, political, or personal - that prevent one from publicly rejecting what they don't accept. 
sincerely assert (2) and yet be in favor of pulling alarms for fun. Similarly, to assert to (3) does not commit one to avoiding that kind of action. This is the underlying intuition behind the linguistic criteria that we propose below in order to distinguish terms with expressive meaning, such as 'horrible', from terms such as 'uncommon' or 'illegal'.

Before we turn to the criteria, let us forestall a possible objection. One could point out that adopting and altering one's practical commitments is a general effect of using language to exchange information. In turn, one might doubt that this feature could be a reliable guide to expressive meaning. Consider again (3). A hearer who learns that pulling a fire alarm for fun is illegal will also typically avoid doing that sort of thing. So it may seem that (3), too, alters the practical commitments of the audience who accepts it; and yet, we would probably not want to say that 'illegal' has an expressive meaning or that it calls for an expressivist account. What is legal and what isn't is clearly a matter of facts (viz. facts about the law).

Although factual statements may also alter one's practical commitments, what is crucial is that they do so in a very different way than expressive statements do. In the case of (3), a person's practical decision not to pull fire alarms for fun does not result simply from learning that this is illegal, but, crucially, from that together with their desire and intention to comply with the law. If there were no such desire or intention, merely learning that something is illegal would not imply - as a matter of practical inference - that one ought to avoid it or condemn it. The remarkable feature of expressive language is that it already incorporates such desires or intentions: if a person sincerely judges that it is horrible to do something, then this directly leads them to avoid and condemn doing that thing. In the case of factual language, by contrast, we always need a bridging premise, such as 'If $\mathrm{X}$ is illegal, then don't do $\mathrm{X}$ '. In the case of expressive language, a premise that says 'If $\mathrm{X}$ is horrible, then don't do $\mathrm{X}$ ' would be redundant, for it is already built in the expressive meaning of 'horrible'.

Based on these considerations, we propose two criteria that can help determine whether the meaning of the expression under consideration is expressive, or rather, factual.

\subsection{Juxtaposition with 'although'-type connectives}

We will start by illustrating the first criterion with two minimal pairs, where a-sentences involve a term with expressive meaning, and b-sentences, a term with factual meaning:

a. Mehmed thinks that providing open access for philosophy journals is a wonderful idea, although he doesn't have any intention or plan whatsoever of supporting or promoting it. 
b. ?? Mehmed thinks that providing open access for philosophy journals is a recent idea, although he doesn't have any intention or plan whatsoever of supporting or promoting it.

a. Nassim thinks that eating meat is wrong, although she consumes twice more meat than average.

b. ?? Nassim thinks that eating meat is unpopular, although she consumes twice more meat than average.

We see that the $a$-sentences are perfectly acceptable, but the $b$-sentences sound marked. Why is this so? We venture that the oddness is due to the connective 'although', which requires a contrast between its arguments. To describe Mehmed as having a highly positive attitude towards an idea - thinking that it is a wonderful idea - and at the same time attribute to him a behavior that fails to promote the idea at stake provides a contrast that licenses the connective 'although'. A similar contrast can be found in describing Nassim as having a highly negative attitude towards an action - thinking that it is wrong to eat meat - and at the same time attributing to her that very sort of action. On the other hand, beliefs about matters of fact - thinking that an idea is recent, or that something is an unpopular thing to do - do not contrast with practices or practical intentions in any direct or immediate way. Since there is no contrast to license the connective 'although', the sentences sound awkward.

We propose the following generalisation. Let $t$ be any term:

(G1) If a sentence of the form 'A thinks that $\mathrm{x}$ is $t$, although A has no desire or intention to support or promote $\mathrm{x}$ ', or of the form 'A thinks that $\mathrm{x}$ is $t$, although $\mathrm{A}$ is willing to support or promote $\mathrm{x}$ ', is felicitous, and is so in the absence of any specific contextual background, then $t$ has expressive meaning. Otherwise $t$ has factual meaning.

We need the qualification 'in the absence of any specific contextual background' to avoid overgeneralising. For there are many uses of 'although' licensed by contrasts that come from contextual information. For instance, if it is common ground that Mehmed would support just any idea as long as it is a recent idea, then (4b) becomes felicitous in such a context.

\subsection{Cogency of practical inferences}

It is well-known that cogent practical inferences (that is, inferences whose conclusions are courses of action, or at least attributions of intentions to engage in some course of action) require 
at least one premise concerning the practical stance of their agent. For example, we accept chains of inferences such as the following:

(6)

a. It's raining.

b. You are going out.

$\therefore \quad$ Take an umbrella.

But it is clear that, as it stands, that inference is only cogent as an enthymeme whose elided premise is something like you do not want to get wet, or something like it is a bad idea to get wet:

a. It's raining.

b. You are going out.

c. You don't want to get wet.

$\therefore$ Take an umbrella.

(8)

a. It's raining.

b. You are going out.

c. It's a bad idea to get wet.

$\therefore \quad$ Take an umbrella.

No premise void of some reference either to the desires, intentions or plans of the agent, or to what is valuable, could do the trick and make the inference cogent. But note that there is a crucial difference between (7) and (8): the former introduces as its elided premise an attribution of a propositional attitude (a desire), while the latter introduces a sentence with expressive meaning, but says nothing about desires, plans or intentions. Regardless, the inference in (8) goes through. 
The idea, then, is that sentences that have expressive meaning are the only type of non-attitudinal premise that can make a chain of practical inference cogent. ${ }^{18}$ We propose the following generalisation:

(G2) Let $A_{1}, \ldots, A_{n}, B \therefore C$ be a cogent practical inference, such that $A_{1}, \ldots, A_{n}$ have factual meanings, and none of them is about the agent's practical attitudes or intentions. Then, if B is not explicitly about the agent's practical attitudes or intentions either, then B has expressive meaning.

\section{The (lack of) epistemic grounds for expressive meaning}

Factual statements can clearly be challenged and supported by evidence. It is not obvious how the same could hold for expressive statements, given that they express the speaker's direct positive or negative attitude or appreciation. The hearer may question the speaker's sincerity, but it would be prima facie weird for them to question the speaker's epistemic evidence for the attitude that they have. Attitudes of being in favor or against something are not based (at least, not directly) on epistemic evidence. Of course, we may dislike someone because of what we believe that this person has done, or we may be in favor of some action because of the factual information that we have regarding the action's outcomes. But this still leaves a wide gap between the epistemic requirements on factual vs. expressive statements. We shall take this as our lead in proposing three criteria that help determining whether a term under consideration has expressive or factual meaning.

\subsection{Lack of epistemic justification}

The first in this second set of criteria relies on the appropriateness of challenging the speaker's evidence. When a sentence has expressive meaning, challenging one's evidence will sound odd; when it has factual meaning, it will sound natural, as the following examples illustrate. Suppose that Militza and Farid have just seen a film together, and the following exchanges take place:

(9) Militza: This film is horrible.

Farid: \# How do you know?

(10) Militza: This film is a remake of an old Italian film.

Farid: How do you know?

\footnotetext{
18 A similar point can be found in Chrisman (Matthew Chrisman, 'Two nondescriptivist views of normative and evaluative statements' Canadian Journal of Philosophy 48(3-4) (2018), 405-424), who proposes to think of the practical commitments associated with normative language in terms of commitments to reason practically in certain ways, that is, to accept certain considerations as reasons for action.
} 
In (9), Farid's quest for Militza's evidence for her statement is utterly inappropriate; not so in (10). We take this to indicate that the statement in (9) is expressive, while the statement in (10) is factual.

It may be worth of stressing that 'How do you know?' is not always an inappropriate follow-up on expressive statements. To wit:

(11) Militza: Sorrentino's latest film is horrible.

Farid: How do you know?

Militza: Because I've seen it.

(12) Militza: That lactose-free yogurt that they've been advertising is delicious.

Farid: How do you know?

Militza: Because I've tried it.

The reason why (11) and (12) sound fine is that we imagine them to be taking place in contexts in which there is no prior knowledge that the speaker has had access to the things about which they are expressing their (lack of) appreciation. We easily hear (11) in a context in which the film at stake hasn't been released in theatres yet, and (12), in a context in which the yogurt hasn't been on sale for long. By questioning Militza's evidence, what Farid is questioning is whether she has had a direct experience of the object on which her evaluation bears. ${ }^{19}$ But this does not amount to questioning her factual evidence.

An effect similar to the 'how do you know?' question can be achieved with other sentences that question one's epistemic evidence, such as 'are you sure?', 'how certain are you?', or 'I doubt that's the case'. Let us call such expressions, epistemic evidence questioning devices. Then the following generalisation can be made:

(G3) Let A be a statement followed by an epistemic evidence questioning device. Then, unless the device is interpreted as questioning the speaker's acquaintance with the object

\footnotetext{
19 The idea that aesthetic judgments as well as judgments of taste somehow imply that the judge has had a first-hand experience of the object at stake is not altogether uncontroversial, but some privileged link between such judgments and acquaintance has to be recognised. It would take us astray to go into the details of this issue; for discussion, see Tamina Stephenson, 'Judge dependence, epistemic modals, and predicates of personal taste', Linguistics and Philosophy 30 (4) (2007): 487-525; Hazel Pearson, 'A Judge-Free Semantics for Predicates of Personal Taste', Journal of Semantics 30 (2013), 103-154; Dilip Ninan, 'Taste Predicates and the Acquaintance Inference', Proceedings of SALT 24 (2014), 290-309; Nils Franzén, 'Aesthetic Evaluation and First-Hand Experience', Australasian Journal of Philosophy 96 (2018), 669-682.
} 
that they are talking about, the exchange is felicitous if $\mathrm{A}$ is a factual statement, but markedly less so if A is an expressive statement.

\subsection{Lack of lying potential}

In the case of factual statements, external evidence may reveal the speaker to have lied to their audience. Expressive statements lack this property, since, again, that sort of evidence can hardly speak against a subjective appreciation. The second criterion that we propose relies on the appropriateness of accusing the speaker of lying. We can illustrate it using the same example as before:

(13) Militza: This film is horrible.

Farid: \# That's a lie!

(14) Militza: This film is a remake of an old Italian film.

Farid: That's a lie!

Hence the following generalisation:

(G4) Factual statements can be lies; expressive statements cannot.

\subsection{Faultless disagreement}

The last criterion that we would like to propose is related to a vexed issue from the literature: that of so-called faultless disagreement. In the early 2000's, the idea of faultless disagreement was put forward to motivate a relativist account of certain types of discourse, regarding personal taste, epistemic modals, moral discourse, and even vagueness. ${ }^{20}$ Relativists would say that, unlike disagreements about facts, in which one of the parties must be wrong, disagreements over matters of taste (or similar matters) are such that neither party need be wrong. They would also say that such disagreements are genuine disagreements, but ones that cannot be settled by appeal to matters of fact.

\footnotetext{
${ }^{20}$ Max Kölbel, Truth Without Objectivity. Routledge (2002); Andy Egan, John Hawthorne and Brian Weatherson, 'Epistemic Modals in Context', in Gerhard Preyer and Georg Peter (Eds.), Contextualism in Philosophy, Oxford University Press (2005), 131-168; Peter Lasersohn, 'Context dependence, disagreement, and predicates of personal taste', Linguistics and Philosophy 28 (2007), 643-686; Mark Richard, When Truth Gives Out. (Oxford University Press, 2008).
} 
We have always been extremely skeptical about the relativists' line of argument. ${ }^{21}$ Nevertheless, we think that there is something to the intuition of faultlessness when it comes to disagreeing about things toward which the disagreeing parties have divergent attitudes. If your best friend loves football, but you dislike it, it would be strange to think that one of the two of you must be wrong. Still, there is a certain disagreement between you regarding football - a disagreement in attitude. ${ }^{22}$ Such a disagreement contrasts sharply with factual disagreement. To illustrate the difference, imagine that Nassim and Mehmed are together at a football match between Barça and Real Madrid and have just witnessed Barça's first goal. Compare the following dialogues:

(15) Nassim: That goal is broad-casted live.

Mehmed: No, it isn't.

(16) Nassim: Wow, (that goal is) incredible!

Mehmed: ?? No, it isn't.

The disagreements in (15) is an ordinary disagreement about facts: to resolve it, all it takes is whether the goal is indeed broad-casted live. On the other hand, Mehmed's reaction to Nassim's enthusiastic expression of amazement sounds completely off. For one thing, a sheer exclamation of the form 'incredible' does not even licence the denial particle 'no'. But even if the speaker uses the full sentential form 'that goal is incredible', then, in the context under consideration, Mehmed's putative denial can at best be seen as a grumpy killjoy's reaction, and it stands in a sharp contrast to genuine denials like (15). ${ }^{23}$

Here is another example:

\footnotetext{
${ }^{21}$ For our criticisms of relativist accounts of disagreement, see Isidora Stojanovic, 'Talking about Taste: Disagreement, Implicit Arguments, and Relative Truth', Linguistics and Philosophy 30 (2007): 691-706, where the focus is on Lasersohn's proposal, and 'When (True) Disagreement Gives Out', Croatian Journal of Philosophy 32 (2011): 181-193, where the focus is on Richard's proposal. See also Isidora Stojanovic, 'Context and Disagreement', Cadernos de Estudos Linguísticos 59 (2017): 7-22, for a discussion of certain complexities of the relevant notion of disagreement that have come to surface over the last two decades.

22 The idea of a disagreement in attitude comes from Stevenson (1937; op. cit.); for more recent discussions, see e.g. Teresa Marques, 'Disagreeing in Context', Frontiers in Psychology 6 (2015), 257; John Eriksson, 'Expressivism, Attitudinal Complexity and Two Senses of Disagreement in Attitude', Erkenntnis 81 (2016), 775-794.

23 To forestall a possible confusion, we are not saying that any dialogue of the form 'This is incredible. - No, it isn't' is infelicitous or marked. Rather, we claim that in contexts in which the speaker uses 'incredible' to express their attitude of amazement, such putative denials sound off. An interlocutor who does not share the speaker's attitude will voice their disagreement by other means; they might use an interjection like 'phew', or a face expression that says 'I am not impressed'. However, we shall return to 'incredible' in section 4.2., where we will see that this adjective can also be used factually - and, when so used, pattern along the lines of (15) rather than (16).
} 
(17) Militza: Sticking chewing-gum into your neighbours' key-holes is illegal.

Farid: No, it isn't.

(18) Militza: Sticking chewing-gum into your neighbors' key-holes is pathetic!

Farid: ?? No, it isn't.

Again, to resolve the disagreement in (17), all it takes is to check whether the laws that apply in the context of Militza and Farid's exchange make any such prohibitions regarding the sticking of chewing-gum. On the other hand, (18) sounds marked, since Militza is expressing her (negative) attitude towards that kind of action, and it makes little sense for Farid to deny such an attitude.

There is, then, a visible contrast between factual and expressive discourse when it comes to disagreement. If the two parties are rational, then gathering sufficient external evidence will typically resolve the disagreement over factual matters, but not so over expressive matters; let us call the latter kind of disagreement 'faultless'. Then we can make the following generalisation:

(G5) Expressive statements give rise to faultless disagreements; factual statements do not.

Two remarks are in order. First, we are not necessarily claiming that only expressive statements can give rise to faultless disagreements. For instance, statements including vague predicates are often taken to do so, too. Consider Nassim and Militza who have different incomes and different standards for what they would reasonably pay for an ordinary meal. After getting a bill of $30 €$ each, one says 'This meal is expensive', and the other replies, 'No, it isn't' (and then generously pays for her friend). Their disagreement (at a first glance, at least) looks faultless. But must this endow 'expensive' with expressive meaning? Not necessarily. What is happening here is, rather, that in the context of their exchange, there is no price range agreed upon to decide when a meal counts as expensive. ${ }^{24}$ Second, we are not the first ones to suggest that intuitions about faultless disagreement may serve as a linguistic criterion. Recently in semantics, several experimental studies on adjectives have used tests that measure speakers' intuitions about disagreement. ${ }^{25}$

\footnotetext{
${ }^{24}$ For discussion, see Chris Barker, 'The dynamics of vagueness', Linguistics and Philosophy 25 (2002), 1-36. Disagreements of the sort are often taken to be instances of so-called 'metalinguistic negotiation'; see David Plunkett and Timothy Sundell 'Disagreement and the Semantics of Normative and Evaluative Terms', Philosophers' Imprint 13(23) (2013), 1-37.

25 Stephanie Solt, 'Multidimensionality, subjectivity and scales: experimental evidence', in Elena Castroviejo, Louise McNally \& Galit Weidman Sassoon (Eds.), The semantics of gradability, vagueness and scale structure: Experimental perspectives. Cham: Springer (2018), 59-91; Federico Faroldi and Andrés Soria Ruiz, 'The Scale Structure of Moral Adjectives' Studia Semiotyczne 31(2) (2017), 161-78; Elsi Kaiser and Catherine Wang, 'Fact or opinion?: An experimental investigation on the recognition of evaluative content', manuscript.
} 


\section{Expressive and factual uses of expressive and factual terms}

The preliminary outcome of the previous sections is that there exists a class of terms (in particular, adjectives), expressive terms, which have two sets of features that set them apart from run-of-the-mill factual terms. First, expressive terms are action-guiding. We have attested actionguidance by (a) the admissibility of 'although'-constructions ascribing to an individual an evaluative stance and incoherent practical attitudes - generalisation (G1) - and (b) the capacity of expressive statements to replace ascriptions of intentions or desires in practical inferences while preserving their cogency - (G2). Secondly, expressive terms are epistemically 'groundless', that is, it is odd to ask for evidence for or against a statement containing an expressive term. We have attested this feature by observing that (a) it is odd to reply to a statement containing an expressive term by targeting the speaker's evidence for their claim; (b) it is odd to accuse the speaker of lying; and (c) disagreements concerning the applicability of an expressive term appear to be faultless.

A natural conclusion to draw at this point is that the afore-discussed criteria single out a class of terms. However, our conclusion is more nuanced. In this section, we want to show that those features are more appropriately associated with certain uses of terms, rather than with the terms themselves. We will support this hypothesis by first showing that expressive terms can have factual uses, and then showing that factual terms can have expressive uses.

\subsection{Expressive terms can have factual uses}

Expressive terms can behave like factual terms in situations that meet the following conditions: first, speakers have to share a standard of evaluation for the relevant term. That is, speakers need to have the same view about what is beautiful, horrible, incredible, and so on. And secondly, speakers have to fail to share first-hand knowledge of the object(s) under evaluation.

Let us think of one such situation. Suppose that Militza and Farid are film critics who know each other very well - so well that, as a matter of fact, they always agree on their judgments about films. By all means, they have the same taste in films. Suppose further that Militza watches a film, and then tells Farid, who has not seen it yet:

(19) [Context: Militza and Farid have the same taste in films; Militza has seen the film, while Farid has not]

Militza: This film is horrible.

We want to argue that, in this situation, Militza's statement behaves like a factual statement. In other words, it is as though she had uttered (20): 
(20) Militza: This film scores poorly relative to our shared taste.

This can be seen by observing the following: first, (19) does not, in this setting, have the same action-guiding properties that sentences containing the word 'horrible' usually have; and secondly, (19) is not (in this setting) epistemically 'groundless'. Let us look at each of these features in turn.

First, let us consider action-guidance. In section 2, the action-guiding properties of expressive terms were attested by first considering their role in 'although'-constructions that establish a contrast between thinking that an expressive term applies and having certain practical attitudes; and then by considering the role of expressive terms in practical inferences.

All this applies to uses of expressive terms in situations such as the one described in (19): in that situation, it would be incoherent for Militza to have a positive practical attitude towards the film, and moreover the sentence in (19) can play the type of role that we have attributed to it in practical reasoning: for Militza to judge that the film is horrible should be a reason not to watch it again, not to recommend it to anyone, and so on. So (19) does not defy generalisations (G1) and (G2).

How can we say, then, that the sentence in (19) is not action-guiding? What we want to defend is not exactly that the sentence in (19) is not action-guiding at all, but rather, that in a situation like the one described in (19), a sentence like 'this film is horrible' is action-guiding only in virtue of previous practical commitments already adopted by the participants in the conversation, and not in virtue of its uptake. In other words, we want to defend that, in a situation like (19), this sentence does not alter the practical commitments of speakers.

To see this, consider the contrast between Militza's utterance in the situation described in (9) and her utterance in (19). In (9), where Militza and Farid are both watching the film and they do not take themselves to have the same taste in films, the practical commitments of interlocutors change as a result of Farid's uptake of Militza's utterance: by accepting Militza's utterance, Farid comes to adopt a taste in films relative to which the film counts as horrible. In a situation like (19), by contrast, the practical commitments of the interlocutors remain unaltered after Farid's uptake of Militza's utterance. Farid's taste and attitudes regarding films do not change as a result of accepting Militza's utterance. Her utterance has therefore the same conversational effect as (20).

Let us press this point. If in (9) Farid is convinced by Militza's statement that the film is horrible, then he adopts a commitment to orient his action in a way that coheres with his newly acquired opinion. This can be spelled out in a variety of ways: Farid might seek to avoid discussing the film in a positive way, he will not recommend it to other people, if given the chance to watch it 
again, he will refuse, and so on. All of these are commitments that Militza, in (9), presumably already had (or more precisely, acquired while watching the film), and that form the basis for her initial judgment that the film is horrible.

By contrast, if Farid accepts Militza's statement in (19), he does not thereby acquire any new practical commitment, nor does he change the commitments that he already had. We have intentionally set up (19) in such a way that Militza and Farid share a taste in films. In virtue of that, Militza and Farid already share certain practical commitments towards films that meet their shared taste to various degrees. If Farid interprets Militza's utterance as an evaluation that is being made relative to their common standard, he does not change his standard by virtue of accepting Militza's utterance in that context, and his practical commitments are not altered either. Rather, Farid only learns that this film has features that fail to meet his previously adopted standard. It is as though Militza had informed him of some fact about the film that he ignored, such as the fact, say, that the film was a remake.

Before moving on, a potential confusion should be pointed out: both in situations (9) and (19), the exchange - if Militza's utterance is accepted — results in the adoption, on the part of both her and Farid, of certain practical commitments towards the very objects under evaluation, namely this film. In both contexts, Farid will come to adopt a negative outlook towards the film, if he accepts Militza's utterance. So the contrast that we want to point out here cannot be spelled out in terms of the interlocutors' practical attitudes towards the film at the end of the exchange, because those attitudes will turn out to be relevantly similar in both situations. Rather, the contrast between the situations described in (9) and (19) is best fleshed out by considering the way in which Farid comes to have that attitude: in (19), it is the result of antecedently held practical commitments; in (9), that attitude results from accepting Militza's utterance, and in virtue of that coming to acquire new practical commitments. We therefore conclude that in a situation like (19) an expressive term can be used in a way that is similar to a factual term.

Next, let us consider the epistemic grounds of a statement like the one in (19). We argued that expressive terms lack epistemic ground, and we tested this via the acceptability of replies that target the speaker's evidence for their claim, the possibility of interpreting their statement as a lie and the intuition that a disagreement involving the relevant term would appear to be faultless. We want to argue that, per these tests, a sentence such as 'this film is horrible', when uttered in a situation such as the one described in (19), does not have expressive meaning.

First, note that in contrast to the situation described in (9), the situation described in (19) makes 'epistemic' answers considerably more natural:

(21) [Context: same as (19)] 
Militza: This film is horrible.

Farid: Are you sure? / How certain are you? / I doubt that's the case.

In (9), in light of the fact that Farid and Militza have no reason to think that they share a taste in films and the fact that they both have seen the film, it was odd for Farid to challenge Militza's evidence for evincing what looks like her opinion. But that reply is significantly more natural in (19), where they know that they share a taste in films. Of course, we need to suppose that Farid has independent reason to distrust Militza's statement about the film. If that is so, then it makes sense for him to challenge her utterance by targeting her evidence for making it.

Secondly, whereas Militza's utterance in the situation described in (9) lacks the potential to be interpreted as a lie, in the situation described in (19) things are different. ${ }^{26}$ To see this, suppose that in (19) Farid eventually gets to watch the film and turns out to disagree with Militza's claim that the film is horrible. In that case, it does make sense for him to accuse Militza of lying:

(21) [Context: same as (19) + Farid has seen the film]

Farid: Hey, the film was not horrible. You lied to me!

We conclude that Militza's utterance in (19) does have lying potential, while her utterance in (9) does not.

Finally, in a situation like (19), if Farid came to disagree with Militza's claim, their disagreement would not be so easily interpreted as faultless, but rather, it would be more naturally interpreted as a disagreement with respect to how badly the film fares relative to their presumably shared taste. It is then comparatively more natural to think that their dispute concerns an issue about which one of them must be wrong.

(22) [Context: same as (19) + Farid has seen the film]

Militza: So you finally saw the film. It was horrible, right?

Farid: Not at all!

What could ground Farid's dissent in this context? It is reasonable to think that Farid is either challenging his and Militza's common taste for films, or he thinks that relative to their common

\footnotetext{
${ }^{26}$ Hare, in The Language of Morals (op. cit, 113 and ff) used this test to argue in favor of the view that an evaluative term like 'good' could be used in the same way as a descriptive term like 'red'. See also Carla Umbach, 'Evaluative propositions and subjective judgments' in Cécile Meier and Janneke van Wijnberger-Huitink (Eds.), Subjective Meaning: Alternatives to Relativism, 127-68 (De Gruyter, 2016).
} 
taste, the film should not count as horrible. In the first case, the disagreement would appear faultless, but the context would no longer be one in which Farid's taste is in complete alignment with Militza's, since he would be trying to alter her taste with his utterance. In the second case, their disagreement would turn on the properties of the film relative to their common taste. In this sense, their disagreement would not be faultless. ${ }^{27}$

We conclude that, given the set of criteria laid out in sections 2 and 3, expressive terms like 'horrible' can have factual uses, whereby they are used to convey factual information and not (mainly) express attitudes. We now turn to showing how standardly factual terms like 'powerful' can behave like expressive terms.

\subsection{Factual terms can have expressive uses}

We have seen that paradigmatically expressive words, such as the adjective 'horrible', can and often do have factual uses. Our next goal is to show that, conversely, paradigmatically factual words, such as the adjectives 'powerful' or 'intense', can and often do have expressive uses. To most readers, this claim should not sound controversial. As we know from aesthetic literature, expressions such as 'powerful' are customarily taken to express aesthetic judgments. Frank Sibley famously proposed the following list of aesthetic concepts: unified, balanced, integrated, lifeless, serene, somber, dynamic, powerful, vivid, delicate, moving, trite, sentimental, tragic, graceful, delicate, dainty, handsome, comely, elegant, garish, dumpy, and beautiful. ${ }^{28}$ Most of these expressions, however, are first and foremost factual. ${ }^{29}$ How and when do those expressions with primarily factual meanings, such as 'unified' or 'balanced', acquire an aesthetic meaning? Sibley himself thinks that there need not be any definite answer to this question. He writes: "It may often be questionable whether a term is yet being used aesthetically or not. Many of the terms I

\footnotetext{
${ }^{27}$ One might object, however, that in situations like (19), where interlocutors share a standard, they can still have a faultless disagreement. This might be because their taste is not fully determined, in the sense that it does not apply to all potential objects of evaluation; or because the objects under consideration are borderline cases for the application of the shared taste. To be more precise, then, our claim is that whenever the shared taste is neither underdetermined nor vague, the corresponding disagreements are not faultless.

28 Frank Sibley, 'Aesthetic Concepts', The Philosophical Review 68(4) (1959), 421-450.

29 To take just the first item in the list, among 50 random hits in a corpus search of the British National Corpus, not a single one corresponded to aesthetic use; for details, see Isidora Stojanovic, 'Expressing Aesthetic Judgments in Context', Inquiry 59 (2016), 663.
} 
have mentioned may be used in ways which are not straightforwardly literal but of which we should hesitate to say that they demanded much yet by way of aesthetic sensitivity." 30

We would like to show that the criteria put forward in sections 2 and 3 can help settle whether a term that is paradigmatically factual is being used, on a given occasion, as an aesthetic concept. Although we will be focusing on aesthetic discourse, our point naturally carries over to uses of factual terms in other areas of expressive discourse. For example, a term like 'appalling' may be said to have a primary factual meaning: it applies to whatever causes terror and dismay. But on many occasions, the term is used to express one's highly negative (often moral) attitude towards an object, as when we say 'What he did is appalling'.

We now turn to applying systematically our five criteria in order to demonstrate the difference between factual and expressive uses of primarily factual words, such as 'powerful' and many of those that figure in Sibley's list. Compare the following two situations:

(23) [Context: Mehmed is making a début as a film director; he wants to send his first film to someone who could help him launch a career. He asks Nassim, who knows the industry well.]

Nassim: Almodóvar is powerful.

(24) [Context: Mehmed and Nassim are in a conversation about European cinema, talking about films and directors that they think are (aesthetically) the best.]

Nassim: Almodóvar is powerful.

Intuitively, the sentence 'Almodóvar is powerful' has very different meanings in (23) and (24). In (23), it states a fact about Almodóvar, namely, that he is someone who has considerable power in the film industry. In (24), on the other hand, the sentence gives expression to a value judgment about Almodóvar's artwork. 'Powerful' becomes a thick term that allows the speaker to express a positive attitude toward Almodóvar qua film director, and toward his films. This intuitive difference, as we are about to show, is confirmed by all five criteria.

First, in the test with 'although'-constructions, a factual use of 'powerful' does not contrast with failing to act in favor of the object described as such, but an expressive use does. Consequently, 'although' sounds marked in the former case but not so in the latter:

\footnotetext{
30 Sibley 1959, op. cit., 447. Note that Sibley appears to think that aesthetic uses of factual words such as 'unified' or 'powerful' are not 'straightforwardly literal', hence that such words acquire their aesthetic meaning through some kind of metaphorical use. We think that the aesthetic uses of (most) such factual words are as literal as their factual uses. It would take us astray, however, to properly demonstrate this.
} 
(25)[Context: same as (23)]

?? Nassim thinks that Almodóvar is powerful, although she has no desire or intention to support or promote either him or his films.

(26)[Context: same as (24)]

Nassim thinks that Almodóvar is powerful, although she has no desire or intention to support or promote either him or his films.

Second, the two uses pattern differently when it comes to practical reasoning. Suppose that you are deliberating which film to go see, and consider the following inference:

a. There is a film by Pedro Almodóvar, and a film by Roland Emmerich.

b. Almodóvar is powerful.

$\therefore$ Go see Almodóvar.

We claim that the inference will only go through if 'powerful' in (b) is used expressively, but not so if it is used factually. Now, a concern may immediately arise. The inference is set as being about which film to see. But, one may object, the factual use of 'powerful' illustrated in (23) was about Almodóvar the man, not about his films. Couldn't a factual use of 'powerful' play a similar role in inferences that are about Almodóvar himself? After all, the context of (23) was one where Mehmed was deliberating to which director to send his film. Consider:

a. Almodóvar is powerful.

$\therefore$ Send your film to Almodóvar.

While we accept that this is a fine inference, what we want to stress, time and again, is that it is fine only to the extent that there is an elided premise of the form 'You want to send your film to a powerful director'. This shows, in turn, that factual uses of 'powerful', unlike its expressive uses, require some premise that is explicitly about the agent's attitudes for the practical inference to be cogent.

Let us now turn to our three epistemic criteria. First, recall that expressive uses, unlike factual uses, do not require epistemic justification (G3) and are not apt to work as lies (G4). This can be 
checked by looking at the appropriateness of the relevant replies - those in which the speaker's epistemic evidence is being questioned, and those in which the speaker is accused of lying:

(29) [Context: same as (23)]

Nassim: Almodóvar is powerful.

Mehmed: How do you know? / Are you sure? / That's a lie! / You've lied to me.

(30) [Context: same as (24)]

Nassim: Almodóvar is powerful.

Mehmed: \# How do you know? / \# Are you sure? / \# That's a lie! / \# You've lied to me.

If 'powerful' is used to state a fact about Almodóvar, all the replies that test for factuality are felicitous. However, if it is used in an aesthetic judgment about Almodóvar as film director, the replies are no longer felicitous.

Finally, the two uses also pattern differently when it comes to disagreement. Consider the following exchange in the situations described in (23) and (24).

(31) [Context: same as (23)]

Nassim: Almodóvar is powerful.

Mehmed: No, he isn't.

(32) [Context: same as (24)]

Nassim: Almodóvar is powerful.

Mehmed: ?? No, he isn't.

In a context such as (23), there is a matter of fact whether Almodóvar has indeed much power in the film industry; once this fact is established, the disagreement ought to be settled. Of course, as we stressed at the end of section 3.3., there may be a lack of agreement between Nassim and Mehmed on how much power a director must have to count as 'powerful'. But once Nassim and Mehmed agree on a standard, then only one of them can be right. On the other hand, in a context such as (24), in which Nassim is expressing her aesthetic appreciation of Almodóvar, Mehmed's reply will already sound marked. But even if we grant that the phrase 'No, he isn't' can be uttered felicitously, its role is no longer to deny what the other person has said. Rather, its role is to voice a diverging aesthetic judgment, to express a contrary attitude. The fact that Nassim and Mehmed 
have different attitudes toward Almodóvar's cinema does not mean that one of them is wrong, hence the intuition that a disagreement in a context such as (24) is a faultless one.

Given the set of criteria laid out in sections 2 and 3, we see that a factual term such as 'powerful' can have expressive uses. Before we close, we want to anticipate a possible worry, according to which the term 'powerful' would simply be ambiguous. First, note that a vast number of adjectives used in aesthetic discourse - in fact, as already pointed out, most of those that figure in Sibley's list - have primary meanings that are factual, but acquire easily an expressive meaning in aesthetic discourse. It would be highly implausible to systematically posit ambiguity for all such cases. ${ }^{31}$ Second, the phenomenon is far more general. Consider again the term 'incredible', which we used, in section 3.3., to illustrate expressive meaning. That term, too, is endowed with factual meaning: it means something unbelievable, something too far-fetched, too extraordinary to be believed. Just as the sentence 'Almodóvar is powerful' displays a distinction between a factual and an expressive use of 'powerful', the sentence 'that goal is incredible' displays such a distinction for the term 'incredible'. To see this, suppose that Nassim and Mehmed are visual effect engineers, who are creating a video of football match from a picture database, and were asked to trick the viewers into thinking that the match was a real one. As they are revising the video, Nassim realises that one of the goals is just not realistic enough:

(33) Nassim: That goal is incredible.

In (33), unlike what we had in (16), Nassim is making a factual statement about the goal at stake; namely, that there is something about the goal that makes it too difficult to believe, implying that the viewers will likely detect that it is fake. On all five criteria, Nassim's utterance of (33) will pattern like a factual statement: it will lack action-guidance (in the relevant sense), it will be idle in practical inferences, Mehmed will be able to challenge Nassim's epistemic evidence for her statement, accuse her of lying, as well as disagree with her in a way that is no longer faultless. Compare:

(34) [Context: Nassim and Mehmed are visual effect engineerings, trying to produce a video of a match that will look real]

Nassim: That goal is incredible.

Mehmed: No, it isn't. It looks real enough.

(35) [Context: Nassim and Mehmed are watching a football match, as in (16)] Nassim: Wow, that goal is incredible!

\footnotetext{
31 A more nuanced proposal would be to say that, rather than ambiguous, all such terms are polysemous. We have no qualms with the idea that a term's capacity to shift between factual and expressive uses may involve a certain form of polysemy; to the contrary, this would reinforce our point. What we do deny, though, is that it involves ambiguity.
} 
Mehmed: ?? No, it isn't.

\section{Conclusion}

In this paper we have defended that, contrary to suggestions made in the literature about expressivism, there is linguistic evidence of a contrast between terms with expressive meaning and terms with factual meaning. We have devised a set of criteria to distinguish these features, based on the action-guiding properties of expressive terms, the oddness of replying to expressive statements by questioning the speaker's evidence or accusing them of lying and the nature of the disagreements that these terms give rise to. But when we put these criteria to work, we found that, on the one hand, adjectives that one might describe as lexically expressive can have factual uses; and on the other, that lexically factual terms can have expressive uses. While the former point has occasionally been raised in metaethics, the latter has long been recognised in the aesthetic literature. However, no existing proposal to our knowledge has offered any neat account of the differences between the two uses. The battery of linguistic criteria that we are proposing is, we think, a first step toward gaining a more systematic and robust understanding of two kinds of meaning in language, factual and expressive. ${ }^{32}$

\footnotetext{
32 We would like to thank María José Frápolli for putting together this special issue. We are grateful to Nils Franzén and Neftalí Villanueva for comments on an earlier draft, as well as to Carla Umbach, Matthew Chrisman, Mora Maldonado, and Salvador Mascarenhas, for discussion. At the institutional level, we acknowledge support from the grant ANR-17-EURE-0017 FrontCog.
} 